\title{
Comparative Study of Methylene Blue Sorbed on Crude and Monosodium Glutamate Functionalized Sawdust
}

\author{
Renmin Gong, ${ }^{*}$ Xingyan Liu, Min Feng, Jingjing Liang, Wenkai Cai, and Na Li \\ College of Life Science, Anhui Normal University, 1 East Beijing Road, Wuhu, Anhui, P. R. China, 241000
}

(Received April 6, 2008; Accepted September 8, 2008)

\begin{abstract}
In order to enhance its cationic sorption capacity, waste sawdust was functionalized by monosodium glutamate (MG) to produce potentially biodegradable cationic sorbent. The crude sawdust (CS) and functionalized sawdust (FS) were compared for the sorption behaviors against methylene blue (MB) in a batch system. The effects of various experimental parameters (e.g. initial $\mathrm{pH}$, sorbent dose, dye concentration, contact time, and temperature etc.) were investigated and the sorption kinetic and thermodynamic characteristics were elucidated. The MB removal ratio on $\mathrm{CS}$ and on $\mathrm{FS}$ increased as the initial $\mathrm{pH}$ increased, and reached to the maximum value beyond $\mathrm{pH}$ 5 and $\mathrm{pH} 6$ for FS and CS, respectively. For $250 \mathrm{mg} / \mathrm{l}$ of MB solution, a removal ratio of greater than $95 \%$ could be achieved with $2.0 \mathrm{~g} / \mathrm{l}$ or more of FS. The MB removal percentage decreased more significantly on CS than on FS with increasing initial MB concentration. The isothermal data of MB sorbed on CS and on FS followed the Langmuir model and the sorption capacities $\left(Q_{m}\right)$ of CS and FS for MB were 87.7 and $188.7 \mathrm{mg} / \mathrm{g}$, respectively. The MB removal on FS and on CS reached to the equilibrium at about 10 and $36 \mathrm{hr}$, respectively. The MB sorption processes on FS and CS followed the pseudo-first-order rate kinetics. The sorptions of MB on CS and on FS were spontaneous and exothermic processes, and lower temperatures were favorable for the sorption processes.
\end{abstract}

Key words_ _ removal, methylene blue, monosodium glutamate, functionalization, sawdust

\section{INTRODUCTION}

Synthetic dyes have been extensively excreted in the wastewater from different industries, particularly from textile, paper, rubber, plastic, leather, cosmetic, food, and drug industries which used dyes to color their products. It is reported that over 100000 commercially available dyes exist and the global annual production of synthetic dyes is more than $7 \times 10^{5}$ metric tones. $^{1,2)}$ Dye wastewater discharge into environmental water bodies deteriorates the water quality, and may cause a significant impact on human health due to toxic, carcinogenic, mutagenic or teratogenic effects of some dyes or their metabolites. ${ }^{3,4)}$

Some biological and physical/chemical methods have been employed for dye wastewater treatment. In all these methods, the sorption has been found to be economical and effective dye wastewater treatment technology as it can remove various dyes with lower treatment cost. Though the

*To whom correspondence should be addressed: College of Life Science, Anhui Normal University, 1 East Beijing Road, Wuhu 241000, P. R. China. Tel.: +86-553-3850975; Fax: +86553-5991085; E-mail: rmgong.nju@163.com removal of dyes through activated carbon sorption is quite effective, the large-scale application of activated carbon is restricted due to its higher cost and regenerating problems. At present, there is a growing interest in using other low cost sorbents for dye removal. Many lignocellulosic materials, including banana pith, ${ }^{5)}$ coir pith, ${ }^{6)}$ sunflower stalks, ${ }^{7}$ corncob, barley husk, ${ }^{8)}$ kudzu, ${ }^{9)}$ rice husk, ${ }^{10)}$ peanut hull, ${ }^{11)}$ kohlrabi peel, ${ }^{12)}$ lemon peel, ${ }^{13)}$ sunflower seed shell, ${ }^{14)}$ pomelo peel, ${ }^{15)}$ yellow passion fruit waste, ${ }^{16)}$ durian peel, ${ }^{17)}$ pumpkin seed hull, ${ }^{18)}$ coffee husk, ${ }^{19)}$ have been used as low cost dye sorbents. Some lignocellulosic materials also have been chemically modified for improving their sorption capacity. ${ }^{20-23)}$

In this paper, a new biodegradable cationic sorbent was synthesized by activating sawdust with epichlorohydrin, followed by coupling the epoxy-activated sawdust with monosodium glutamate (MG). The comparative study with crude sawdust (CS) and functionalized sawdust (FS) as sorbents for removal of methylene blue (MB) from aqueous solution was conducted in a batch system. The purpose of the present work was to exploit and utilize new low cost sorbent for enhancing 
the treatment of industrial wastewater and reducing the cost of wastewater treatment. To the best of our knowledge, up to now, no cationic sorbent prepared from lignocellulosic material functionalized with low cost MG had been reported.

\section{MATERIALS AND METHODS}

Preparation of FS-Sawdust [Castanopsis sclerophylla (LinDL.) ScHOTT.], supplied by a local wood processing factory, was washed with tap water to remove impurity, and then dried overnight at $50^{\circ} \mathrm{C}$. Dried sawdust was sieved to retain the 420 $850 \mu \mathrm{m}$ fractions for further chemical modification. All chemicals used were of analytical grade except for $\mathrm{MB}, \mathrm{MG}$ and phenolphthalein.

Twenty grams of sawdust were suspended in $240 \mathrm{ml}$ of dioxane (Sinopharm Chemical Reagent Co., Ltd., Shanghai, China). While stirring the suspension on a thermostatic stirrer, $24 \mathrm{ml}$ of $20 \%$ $\mathrm{NaOH}$ was added followed by $40 \mathrm{ml}$ of epichlorohydrin (Shanghai Lingfeng Chemical Reagent Co., Ltd., Shanghai, China) and the reaction suspension was stirred for $5 \mathrm{hr}$ at $65^{\circ} \mathrm{C}$. After keeping it overnight at room temperature, the activation product was collected by suction filtration in a sintered glass funnel and washed thoroughly with dioxane followed by $0.1 \mathrm{~mol} / 1 \mathrm{Na}_{2} \mathrm{CO}_{3}-\mathrm{NaHCO}_{3}$ buffer $(\mathrm{pH}$ 9.5). For the coupling of the functional ligand, the epoxy-activated sawdust was immediately resuspended in dioxane containing $12 \mathrm{~g}$ of $\mathrm{MG}$ (Henan Lianhua Monosodium Glutamate Co., Ltd., Zhoukou, China), and a drop of phenolphthalein (Tianjin Kermel Chemical Reagent Co., Tianjin, China) was added followed by dropwise addition of $20 \% \mathrm{NaOH}$ with stirring until the MG dissolved and pink color appeared. The reaction mixture was stirred for $4 \mathrm{hr}$ at $55^{\circ} \mathrm{C}$ and then left overnight at room temperature. The prepared FS was recovered by suction filtration and washed extensively with distilled water. Subsequently, it was dried at $50^{\circ} \mathrm{C}$ for $24 \mathrm{hr}$ in a forced air oven and preserved in a desiccator for further use as cationic sorbent. The chemical mechanism of preparing FS was given in Fig. 1.

Preparation of MB Solution - MB (Sigma Chemical Co., St. Louis, MO, U.S.A.), a basic dye of phenothiazine type (colour indix number 52015, formula weight $=373.9, \lambda_{\max }=670 \mathrm{~nm}$ ) in highest grade available, was used without further purification. The dye stock solution was prepared by dissolving accurately weighted $\mathrm{MB}$ in distilled water to the concentration of $500 \mathrm{mg} / \mathrm{l}$. All experimental solutions were obtained by diluting the dye stock solution in accurate proportions to different initial concentrations.

Removal Experiments — Removal experiments were carried out in a rotary shaker at $150 \mathrm{rpm}$ and room temperature (except for the experiments of temperature effect) using $250 \mathrm{ml}$ shaking flasks containing $100 \mathrm{ml}$ of different concentrations and initial $\mathrm{pH}$ values of MB solution. The initial $\mathrm{pH}$ values of the solution were previously adjusted with diluted $\mathrm{HNO}_{3}$ or $\mathrm{NaOH}$ using a $\mathrm{pH}$ meter. Different doses of CS or FS were respectively added to the respective flask, and then the flasks were sealed up to prevent change of volume of the solution during the experiments. After shaking the flasks for predetermined time intervals, samples were withdrawn from the flasks and the MB solution was separated from the sorbent by sedimentation/centrifugation. MB concentration in the supernatant solution was estimated by spectrophotometry. The amount of MB sorbed on sorbent was calculated by the mass balance equation.

The effect of each experimental parameter was studied by fixing the values of other parameters. The experiments were conducted in triplicate and negative control (with no sorbent) experiments were simultaneously carried out to ensure that sorption was caused not by the container but by the sorbent. Infrared (IR) Spectra Study — The IR spectra of CS and FS were measured on a Fourier Transform Infrared Spectrometer (FTIR-8400S, Shimadzu) to elucidate the functional groups present-

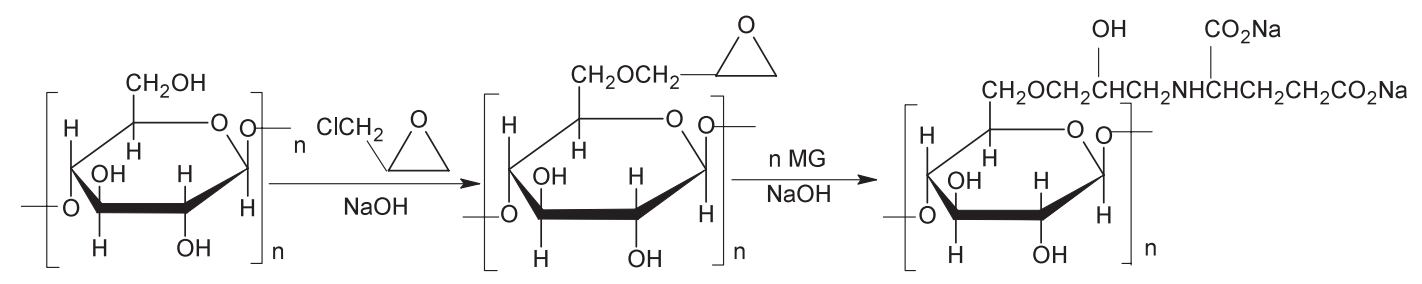

Fig. 1. Chemical Mechanism of Preparing FS 
ing in sawdust before and after functionallization. For measuring IR spectra, $5 \mathrm{mg}$ of powdered CS or FS was encapsulated in $400 \mathrm{mg}$ of KBr. Translucent disk was made by pressing the ground mixed materials with the aid of a bench press $(955 \mathrm{~kg}$ for $10 \mathrm{~min})$.

\section{RESULTS AND DISCUSSION}

\section{IR Spectrum Analysis of Sorbent}

The IR spectra of CS and FS were shown in Fig. 2. By comparing both IR spectra, it could been seen that a new characteristic stretching vibration absorption band of carboxyl group at $1735 \mathrm{~cm}^{-1}$ (band I) and an increased stretching vibration absorption band of amino group at $3375 \mathrm{~cm}^{-1}$ (band II) appeared in IR spectrum of FS. The obvious difference between IR spectrum of CS and FS indicated that the MG had been functionalized into CS.

\section{Effect of Initial Solution pH on MB Removal}

In all experimental parameters affecting $\mathrm{MB}$ sorbed on CS and on FS, the effects of initial $\mathrm{pH}$ were investigated first. The initial $\mathrm{pH}$ of $\mathrm{MB}$ solution was changed over a range from 2 to 10 . As shown in Fig. 3, for both CS and FS, the MB removal ratio was minimal at the initial $\mathrm{pH} 2$. As $\mathrm{pH}$ increased, the MB removal amount increased, and the maximum value of $\mathrm{MB}$ removal appeared in the range of $\mathrm{pH} \geq 5$ for $\mathrm{FS}$ and $\mathrm{pH} \geq 6$ for $\mathrm{CS}$, respectively. For this reason, the $\mathrm{pH} 6$ was selected for the following experiments.

\section{Effect of Sorbent Dosage on MB Removal}

The influences of sorbent dose on the MB re-

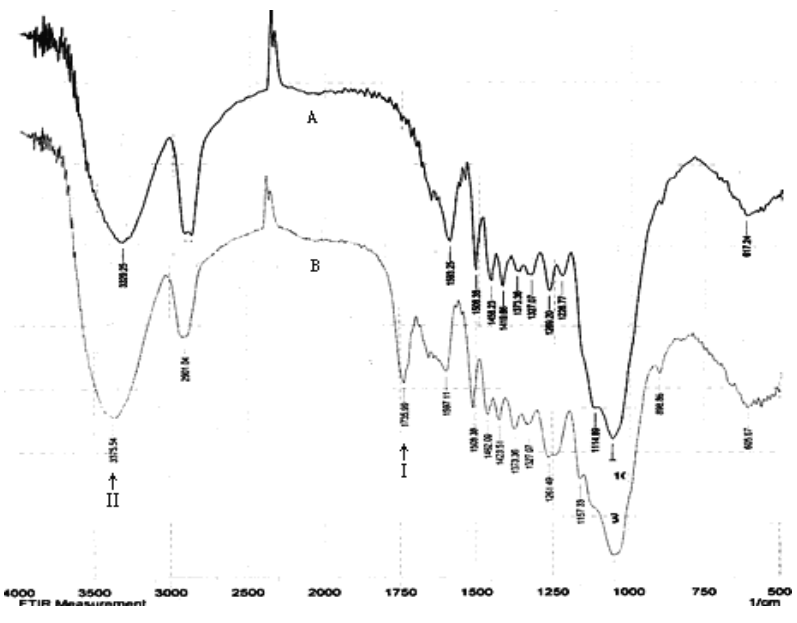

Fig. 2. IR Spectra of Sawdust (A: CS; B: FS) moval ratio on CS and on FS were shown Fig. 4. Along with the sorbent dose was increased from 0.25 to $4.0 \mathrm{~g} / \mathrm{l}$, the percentage of MB sorbed on CS increased from 7.0 to $63.7 \%$. When the sorbent dose was increased from 0.25 to $2.0 \mathrm{~g} / \mathrm{l}$, the ratio of $\mathrm{MB}$ sorbed on FS increased from 13.6 to $95.1 \%$. Increase in the MB sorption ratio with sorbent dose could be attributed to increased sorbent surface area and availability of more sorption sites. Above $2.0 \mathrm{~g} / \mathrm{l}$ of sorbent dose, the uptake of MB on FS reached to the maximum value and the MB removal ratio only vibrated between $95.1-97.7 \%$. The sorbent dosage of $2.0 \mathrm{~g} / \mathrm{l}$ was chosen for the subsequent experiments.

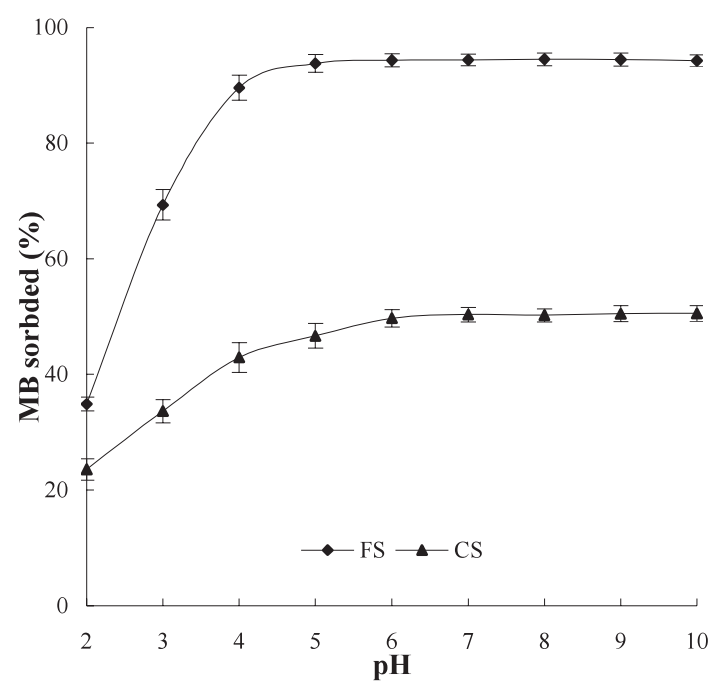

Fig. 3. Effect of Initial Solution $\mathrm{pH}$ on MB Sorption on CS and on FS

MB concentration, $250 \mathrm{mg} / \mathrm{l}$; sorbent dose, $2 \mathrm{~g} / \mathrm{l}$; contact time, $40 \mathrm{hr}$.

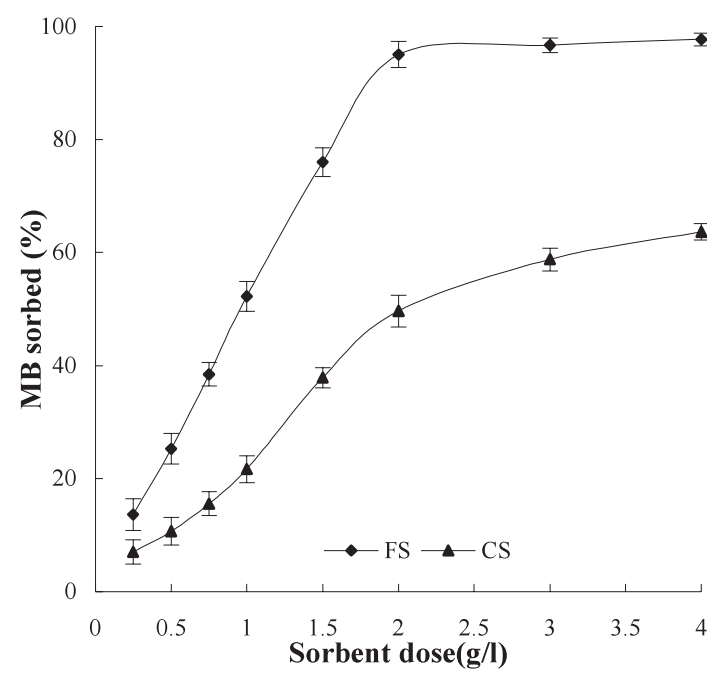

Fig. 4. Influence of Sorbent Dose on MB Sorption on CS and on FS

MB concentration, $250 \mathrm{mg} / 1$; contact time, $40 \mathrm{hr}$; $\mathrm{pH}, 6.0$. 


\section{Influence of Initial MB Concentration on Its Re- moval}

The effects of MB concentration on its sorption percentage on CS and on FS were presented in Fig. 5. When the MB concentration was increased from 50 to $500 \mathrm{mg} / \mathrm{l}$, its sorption percentage on CS sharply decreased from 94.5 to $34.4 \%$. But over a range from 50 to $250 \mathrm{mg} / \mathrm{l}$ of $\mathrm{MB}$ concentration, its removal ratio on FS only decreased a little, from 98.8 to $94.4 \%$. With further increase of MB concentration up to $500 \mathrm{mg} / \mathrm{l}$, its removal ratio on FS further decreased to $73.2 \%$.

With the data in Fig. 5, Langmuir equation was employed to study the sorption isotherm of $\mathrm{MB}$ on $\mathrm{CS}$ and on FS. The linear Langmuir equation was:

$$
C_{e} / q_{e}=1 /\left(a Q_{m}\right)+C_{e} / Q_{m}
$$

where $C_{e}(\mathrm{mg} / \mathrm{l})$ is the concentration of the dye solution at equilibrium, $q_{e}(\mathrm{mg} / \mathrm{g})$ is the amount of dye sorbed at equilibrium, $Q_{m}$ is the sorption capacity and represents a practical sorption limitation when the sorbent surface is fully covered with monolayer sorbate molecules and $a$ is Langmuir constant. The $Q_{m}$ and $a$ values were calculated from the slopes $\left(1 / Q_{m}\right)$ and intercepts $\left(1 / a Q_{m}\right)$ of linear plots of $C_{e} / q_{e}$ versus $C_{e}$.

The isothermal simulation results of MB sorbed on CS and on FS were shown in Table 1. The high values of correlation coefficients indicated that the

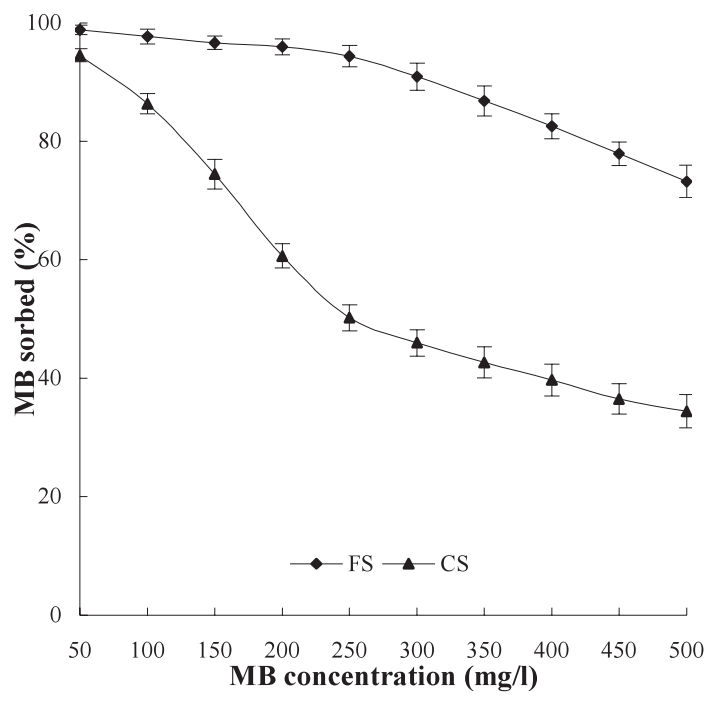

Fig. 5. Effect of Initial MB Concentration on Its Sorption on $\mathrm{CF}$ and on FS

Sorbent dose, $2 \mathrm{~g} / \mathrm{l}$; contact time, $40 \mathrm{hr}$; $\mathrm{pH}, 6.0$. sorption isotherms of $\mathrm{MB}$ on $\mathrm{CS}$ and on FS followed the Langmuir model. After functionalization, the sorption capacity $\left(Q_{m}\right)$ of sawdust for MB was elevated from $87.7 \mathrm{mg} / \mathrm{g}$ to $188.7 \mathrm{mg} / \mathrm{g}$.

\section{Influence of Contact Time on MB Removal and Kinetics}

The influences of contact time on MB removal percentage by CS and FS were illustrated in Fig. 6. The rate of MB removal was very rapid at the initial stage of sorption, caused by the fast diffusion and sorption of dye cation onto the external surface of sorbent. After that, the rate of MB removal declined gradually and reached the equilibrium value at about 10 and $36 \mathrm{hr}$ on FS and on CS, respectively. This process was controlled by the pore diffusion velocity of dye cation into the intraparticle matrix of sorbent.

After chemical modification, the negative electric carboxyl groups were introduced as main active groups of sawdust. The sorption of cationic MB on FS became an ion exchange process. The sorption capacity of the sorbent was increased and the sorption equilibrium time was shortened.

To examine the kinetic models of MB sorbed on $\mathrm{CS}$ and on FS, the following Lagergren's pseudofirst-order rate equation was used to test experimental data:

$$
\lg \left(q_{e}-q_{t}\right)=-k_{a d} t / 2.30+\lg q_{e}
$$

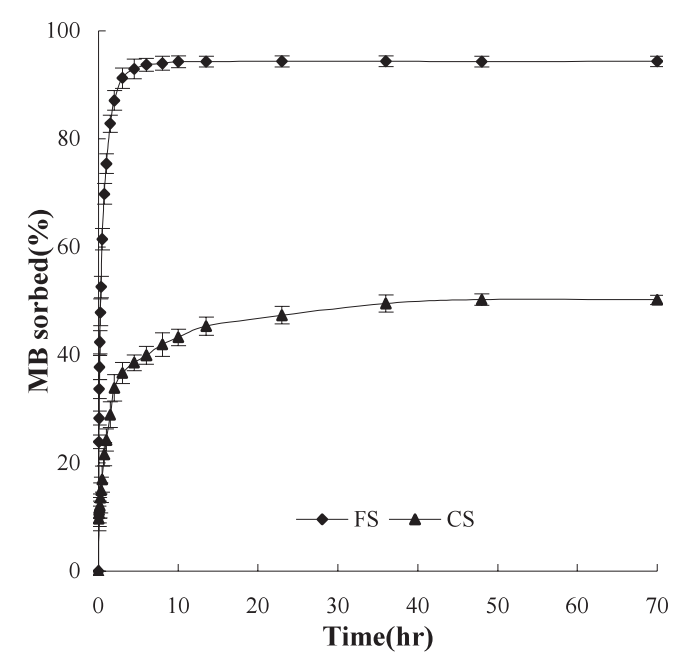

Fig. 6. Influence of Contact Time on MB Sorption on CS and on FS

MB concentration, $250 \mathrm{mg} / \mathrm{l}$; sorbent dose, $2 \mathrm{~g} / \mathrm{l} ; \mathrm{pH}, 6.0$.

Table 1. The Isothermal Simulation Results of MB Sorbed on CS and on FS

\begin{tabular}{llclc}
\hline \hline Sorbent & Langmuir equation & $Q_{m}(\mathrm{mg} / \mathrm{g})$ & \multicolumn{1}{c}{$a$} & $R^{2}$ \\
\hline $\mathrm{CS}$ & $C_{e} / q_{e}=0.0114 C_{e}+0.298$ & 87.7 & 0.0383 & 0.9836 \\
$\mathrm{FS}$ & $C_{e} / q_{e}=0.0053 C_{e}+0.043$ & 188.7 & 0.123 & 0.9972 \\
\hline
\end{tabular}


where $q_{e}$ and $q_{t}(\mathrm{mg} / \mathrm{g})$ refer to the amount of dye sorbed at equilibrium and time $t(\mathrm{~min})$, respectively, and $k_{a d}$ is the rate constant. The $k_{a d}$ values could be calculated from the slopes of the linear plots of $\lg \left(q_{e}-q_{t}\right)$ versus $t$. Based on the experimental data in Fig. 6, the Lagergren's pseudo-first-order rate equations of $\mathrm{MB}$ sorbed on $\mathrm{CS}$ and on FS were respectively described as:

$$
\begin{array}{ll}
\lg \left(q_{e}-q_{t}\right)=-0.0074 t+3.93, & R^{2}=0.9973 \\
\lg \left(q_{e}-q_{t}\right)=-0.0205 t+4.42, & R^{2}=0.9863
\end{array}
$$

The high values of correlation coefficients in the above two equations showed that the experimental data conformed well to the pseudo-first-order rate kinetic model.

\section{Effect of Temperature on MB Removal and Thermodynamics}

The effects of temperature on the MB removal ratio on CS and on FS were shown Fig. 7. The MB removal ratio on $\mathrm{CS}$ and on $\mathrm{FS}$ decreased along with increasing experimental temperature.

The Van't Hoff equation and Gibbs-Helmholtz equation were used to obtain the sorption thermodynamics parameters such as standard enthalpy change $\left(\Delta H^{\circ}\right)$, standard entropy change $\left(\Delta S^{\circ}\right)$, and standard free energy change $\left(\Delta G^{\circ}\right)$.

The values of $\Delta H^{\circ}$ and $\Delta S^{\circ}$ were calculated from the following Van't Hoff equation:

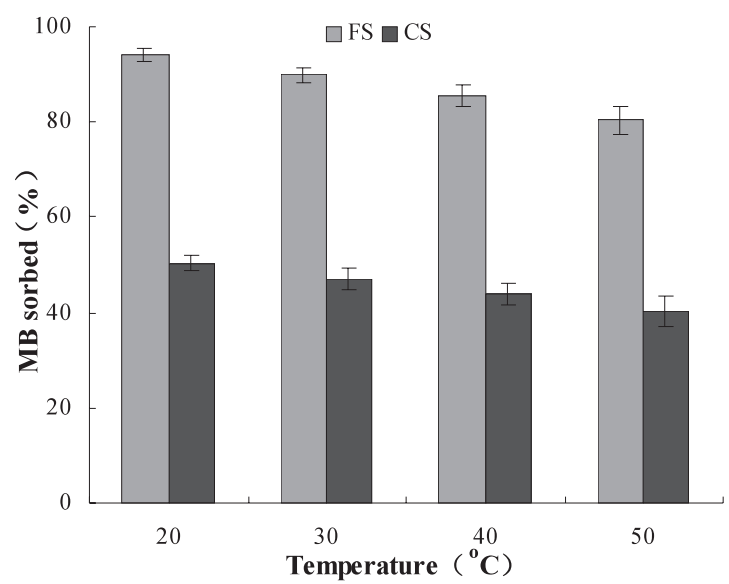

Fig. 7. Effect of Temperature on MB Sorption on CS and on FS

MB concentration, $250 \mathrm{mg} / \mathrm{l}$; sorbent dose, $2 \mathrm{~g} / \mathrm{l}$; contact time, $40 \mathrm{hr} ; \mathrm{pH}, 6.0$ $\ln \left(q_{e} / C_{e}\right)=-\Delta H^{\circ} / \mathrm{R} T+\Delta S^{\circ} / \mathrm{R}$

where $q_{e} / C_{e}$ is the equilibrium constant $(\mathrm{ml} / \mathrm{g}), \Delta H^{\circ}$ is standard enthalpy change $(\mathrm{J} / \mathrm{mol}), \Delta S^{\circ}$ is standard entropy change $(\mathrm{J} / \mathrm{mol} \cdot \mathrm{K}), T$ is the absolute temperature $(\mathrm{K})$, and $\mathrm{R}$ is the gas constant $(8.314 \mathrm{~J} / \mathrm{mol} \cdot \mathrm{K})$. The $\Delta H^{\circ}$ and $\Delta S^{\circ}$ values were calculated from the slope $\left(-\Delta H^{\circ} / \mathrm{R}\right)$ and intercept $\left(\Delta S^{\circ} / \mathrm{R}\right)$ of the linear plot of $\ln \left(q_{e} / C_{e}\right)$ versus $1 / T$. Based on the experimental data in Fig. 7, the Van't Hoff equations of MB sorbed on CS and on FS were respectively given as follows:

$$
\begin{array}{ll}
\ln \left(q_{e} / C_{e}\right)=1281 / T+1.87, & R^{2}=0.9979 \\
\ln \left(q_{e} / C_{e}\right)=4299 / T-5.72, & R^{2}=0.9902
\end{array}
$$

The values of $\Delta G^{\circ}$ was calculated from the following Gibbs-Helmholtz equation:

$$
\Delta G^{\circ}=\Delta H^{\circ}-T \Delta S^{\circ}
$$

where $\Delta G^{\circ}$ is the standard free energy change $(\mathrm{kJ} / \mathrm{mol})$. The $\Delta G^{\circ}$ values under different temperatures as well as $\Delta H^{\circ}$ and $\Delta S^{\circ}$ values were presented in Table 2. The negative values of $\Delta G^{\circ}$ and $\Delta H^{\circ}$ indicated that the sorptions of $\mathrm{MB}$ on $\mathrm{CS}$ and on FS were spontaneous and exothermic. Lower temperatures were favorable for the sorption processes.

In conclusion, this comparative study confirmed that FS was an excellent sorbent for removal of MB from aqueous solution. The MB removal ratio on $\mathrm{CS}$ and on FS increased as the initial $\mathrm{pH}$ was increased and reached to the maximum value beyond $\mathrm{pH} 5$ and $\mathrm{pH} 6$ for FS and CS, respectively. The $\mathrm{MB}$ removal ratio on $\mathrm{CS}$ and on FS increased with increasing sorbent dose but decreased with increasing dye concentration. The isothermal data of $\mathrm{MB}$ sorbed on CS and on FS followed the Langmuir model and the sorption capacities $\left(Q_{m}\right)$ of CS and FS for MB were 87.7 and $188.7 \mathrm{mg} / \mathrm{g}$, respectively. The MB removal on FS and on CS reached to the equilibrium at about 10 and $36 \mathrm{hr}$, respectively. The MB sorption processes on CS and on FS followed the pseudo-first-order rate kinetics. The sorptions of $\mathrm{MB}$ on $\mathrm{CS}$ and on FS were spontaneous and exothermic processes and lower temperatures were favorable for the sorption processes.

Acknowledgements The authors would like to

Table 2. The Thermodynamic Parameter Values of MB Sorbed on CS and on FS

\begin{tabular}{lcccccc}
\hline \hline Sorbent & $\Delta H^{\circ}$ & $\Delta S^{\circ}$ & \multicolumn{4}{c}{$\Delta G^{\circ}(\mathrm{kJ} / \mathrm{mol})$} \\
\cline { 4 - 7 } & $(\mathrm{kJ} / \mathrm{mol})$ & $(\mathrm{J} / \mathrm{mol} \cdot \mathrm{K})$ & $293.2 \mathrm{~K}$ & $303.2 \mathrm{~K}$ & $313.2 \mathrm{~K}$ & $323.2 \mathrm{~K}$ \\
\hline CS & -10.7 & 15.5 & -15.2 & -15.4 & -15.5 & -15.7 \\
FS & -35.7 & -47.5 & -21.8 & -21.3 & -20.9 & -20.4 \\
\hline
\end{tabular}


acknowledge financial support from the Key Project of Natural Science Foundation of Anhui Education Bureau, the Key Laboratory of Bioresource Protection and Utilization of Anhui Province, the Key Laboratory of Biotic Environment and Ecological Safety of Anhui Province, and the BioMacromolecular Evolution Laboratory of Anhui Normal University.

\section{REFERENCES}

1) Pearce, C. I., Lloyd, J. R. and Guthrie, J. T. (2003) The removal of colour from textile wastewater using whole bacterial cells: a review. Dyes Pigments, 58, 179-196.

2) McMullan, G., Meehan, C., Conneely, A., Kirby, N., Robinson, T., Nigam, P., Banat, I. M., Marchant, R. and Smyth, W. F. (2001) Microbial decolourisation and degradation of textile dyes. Appl. Microbiol. Biotechnol., 56, 81-87.

3) McKay, G., Otterburn, M. S. and Aga, D. A. (1985) Fullers earth and fired clay as adsorbent for dye stuffs, equilibrium and rate constants. Water Air Soil Pollut., 24, 307-322.

4) Gregory, A. R., Elliot, S. and Kluge, P. (1991) Ames testing of direct black 3B parallel carcinogenicity. $J$. Appl. Toxicol., 1, 308-313.

5) Namasivayam, C., Kanchana, N. and Yamuna, R. T. (1993) Waste banana pith as adsorbent for the removal of Rhodamine B from aqueous solution. Waste Manag., 13, 89-95.

6) Namasivayam, C. and Kadirvelu, K. (1994) Coir pith, an agricultural waste by-product for the treatment of dyeing wastewater. Bioresour. Technol., 48, 79-81.

7) Sun, G. and Xu, X. (1997) Sunflower stalks as adsorbents for color removal from textile wastewater. Ind. Eng. Chem. Res., 36, 808-812.

8) Robinson, T., Chandran, B. and Nigam, P. (2002) Removal of dyes from an artificial textile dye effluent by two agricultural waste residues, corncob and barley husk. Environ. Int., 28, 29-33.

9) Allen, S. J., Gan, Q., Matthews, R. and Johnson, P. A. (2003) Comparison of optimised isotherm models for basic dye adsorption by kudzu. Bioresour. Technol., 88, 143-152.

10) Vadivelan, V. and Kumar, K. V. (2005) Equilibrium, kinetics, mechanism, and process design for the sorption of methylene blue onto rice husk. $J$. Colloid Interf. Sci., 286, 90-100.

11) Gong, R., Li, M., Yang, C., Sun, Y. and Chen, J. (2005) Removal of cationic dyes from aqueous solu- tion by adsorption on peanut hull. J. Hazard. Mater, 121, 247-250.

12) Gong, R., Zhang, X., Liu, H., Sun, Y. and Liu, B. (2007) Uptake of cationic dyes from aqueous solution by biosorption onto granular kohlrabi peel. Bioresour. Technol., 98, 1319-1323.

13) Kumar, K. V. (2007) Optimum sorption isotherm by linear and non-linear methods for malachite green onto lemon peel. Dyes Pigments, 74, 595-597.

14) Osma, J. F., Saravia, V., Toca-Herrera, J. L. and Couto, S. R. (2007) Sunflower seed shells: A novel and effective low-cost adsorbent for the removal of the diazo dye Reactive Black 5 from aqueous solutions. J. Hazard. Mater., 147, 900-905.

15) Hameed, B. H., Mahmoud, D. K. and Ahmad, A. L. (2008) Sorption of basic dye from aqueous solution by pomelo (Citrus grandis) peel in a batch system. Colloid and Surface A: Physicochemical and Engineering Aspects, 316, 78-84.

16) Pavan, F. A., Lima, E. C., Dias, S. L. P. and Mazzocato, A. C. (2008) Methylene blue biosorption from aqueous solutions by yellow passion fruit waste. J. Hazard. Mater., 150, 703-712.

17) Hameed, B. H. and Hakimi, H. (2008) Utilization of durian (Durio zibethinus Murray) peel as low cost sorbent for the removal of acid dye from aqueous solutions. Biochemical Engineering Journal, 39, 338343.

18) Hameed, B. H. and El-Khaiary, M. I. (2008) Removal of basic dye from aqueous medium using a novel agricultural waste material: Pumpkin seed hull. J. Hazard. Mater., 155, 601-609.

19) Oliveira, L. S., Franca, A. S., Alves, T. M. and Rocha, S. D. F. (2008) Evaluation of untreated coffee husks as potential biosorbents for treatment of dye contaminated waters. J. Hazard. Mater., 155, 507-512.

20) Low, K. S. and Lee, C. K. (1997) Quaternized rice husk as sorbent for reactive dyes. Bioresour. Technol., 61, 121-125.

21) Ong, S. T., Lee, C. K. and Zainal, Z. (2007) Removal of basic and reactive dyes using ethylenediamine modified rice hull. Bioresour. Technol., 98, 2792-2799.

22) Gong, R., Jin, Y., Chen, J., Hu, Y. and Sun, J. (2007) Removal basic dyes from aqueous solution by sorption on phosphoric acid modified rice straw. Dyes Pigments, 73, 332-337.

23) Anirudhan, S. T. and Radhakrishnan, P. G. (2007) Chromium(III) removal from water and wastewater using a carboxylate-functionalized cation exchanger prepared from a lignocellulosic residue. J. Colloid Interf. Sci., 316, 268-276. 